\title{
Sobre agentes infecciosos, zoofitos, animálculos e infusorios
}

\author{
Carlos G. Osorio A.
}

\section{About infection agents, zoophytes, animalcules and infusories}

By definition, zoophytes are organisms with characteristics which are intermediate between plants and animals. The concept is already outlined by Aristotle in his Historia Animalium. In the XVIII century, the great Swedish naturalist Carolus Linnaeus, in the tenth edition of his Systema Naturae, included the order Zoophyta within the class of Vermes. In this classification, for the first time the curious animalcules (infusories), discovered by van Leeuwenhoek in the late XVII century, were formally classified as zoophytes and were incorporated specifically into the genus Chaos. Audaciously, Linnaeus also conjectured that the infectious agents could be related to the animalcules-infusories, though he left the corresponding demostration to posterity.

Key words: zoophytes, animalcules, infusories.

Palabras claves: zoofitos, animalculos, infusorios.

Aristóteles, en su obra Historia Animalium, expresa claramente lo que luego se denominó Scala Naturae o Gran Cadena de los Seres (échelle des êtres). "La naturaleza avanza poco a poco desde lo inanimado hasta la vida animal, de una manera que es imposible determinar exactamente, cuál es el límite de demarcación, ni a qué grupo podrían pertenecer las formas intermedias"1. Aún así, esto no le impidió al gran Estagirita describir a algunas de estas formas intermedias, llamadas por él Ostrakodermos, más conocidos por su nombre latino de Testacea (actuales bivalvos, caracoles, erizos de mar, etc), dentro de los animales.

A inicios de nuestra era, los organismos que poseían características externas de animales y plantas, comenzaron a denominarse zoofitos (latín sing: zoophytum; plural: zoophyta). Esta denominación habría surgido por primera vez en el siglo IV (ca. 350 D.C.) en la escuela neoplatónica siria. Dexippus, discípulo de Iámblico de Calcis, escribió: "La naturaleza no pasa directamente entre categorias, como por ejemplo entre animales y plantas,

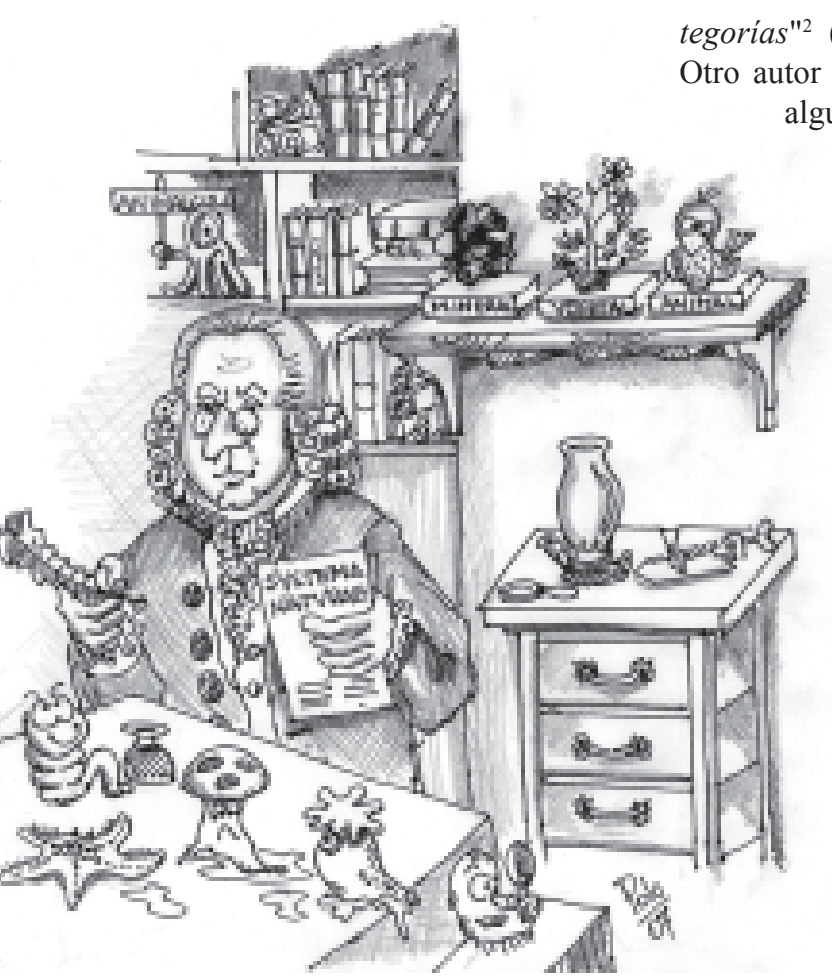

sino que ella tiene que idear un tipo de vida intermedia, tal como los zoofitos que unen ambos extremos y completan asi ambas caanimales no sanguíneos o anaema (los llamados posteriormente invertebrados por Jean-Baptiste de Lamarck) ${ }^{3}$, siendo sus prin- 
cipales representantes, los equinodermos (estrellas de mar), celentéreos (medusas) y esponjas. Por otra parte, Rondelet, en el volumen dos de su célebre obra sobre los peces, incorpora un capítulo completo dedicado a los insectos y zoofitos ${ }^{4}$. Es importante destacar que los zoofitos, a pesar de ser considerados formas intermedias entre el reino vegetal y animal, fueron siempre clasificados por estos autores como animales, continuando la tradición iniciada por el sempiterno Estagirita.

En cuanto a los animálculos (latín: animalculum; plural: animalcula), ¿qué relación podían ellos tener con estos seres de naturaleza intermedia llamados zoofitos? Partamos indicando, entonces, que los animálculos fueron observados por primera vez por el holandés Antoine van Leeuwenhoek en su ciudad natal de Delft, en el verano de 1674 , con la ayuda de una lupa simple (usando un pequeño lente esférico de cuarzo $)^{5}$. La denominación original para estos seres microscópicos fue kleyne dierkens o pequeños animalitos. Este nombre fue traducido al latín como animálculos por su coetáneo y amigo Regnier de Graaf, quien divulgó los descubrimientos de van Leeuwenhoek, traduciendo al latín algunas de sus célebres cartas y enviándolas para su publicación en la revista de la Royal Society de Londres denominada Philosophical Transactions of the Royal Society of London. El primer libro, dedicado casi enteramente a los animálculos, fue publicado en 1718 por el microscopista francés Louis Joblot (1645-1723). Posteriormente, el famoso médico y anatomista alemán, Heinrich August Wrisberg (1739-1808), introdujo en 1765 , por primera vez, el término infusoria (latín sing: infusorium; plural: infusoria) (estrictamente hablando, los infusorios son sólo un subgrupo de los animálculos, pues éstos últimos incluyen, además, otras formas de vida microscópica, tales como los espermatozoides. De aquí en adelante usaremos el término infusorios con el fin de restringir la amplitud del término original).

El médico sueco Carolus Linnaeus (17071778), padre de la taxonomía moderna, publicó gran parte de sus ideas en su libro Systema Naturae per Regna Tria Naturae. En dicha obra intentó sistematizar todo el conocimiento referente a los seres vivos animales, ve- getales y también sobre los minerales, creando los clásicos reinos Animale (animal), Vegetabile (vegetal) y Lapideum (mineral), englobados los tres dentro del denominado Imperium Naturae. Esta obra fue publicada en doce ediciones aparecidas durante la vida de Linnaeus. ¿Dónde localizaría el gran Linnaeus a los infusorios? En la primera edición de 1735, clasificó a algunos infusorios (Volvox) en la clase Cryptogamia del reino Vegetabile, junto a los hongos. Sin embargo, decidió trasladarlos al reino Animale, clase Vermes, orden Zoophyta, en la décima edición de $1758^{3}$. ¿Qué lo impulsó a tomar semejante decisión? Seguramente, la forma alargada de algunos infusorios, su falta de apéndices externos y su importante motilidad, fueron factores decisivos para dicho cambio (todas características de los vermes). ¿Pero, por qué dentro de los zoofitos? Esta pregunta es más difícil de contestar pero, es posible que Linnaeus considerara a los infusorios como seres de características intermedias, siendo algunos muy semejantes a pequeñísimas plantas verdes (microorganismos con clorofila) y otros claramente semejantes a pequeños gusanos (espiroquetas). Es destacable, además, que Linnaeus dividiera a los zoofitos en sésiles y mótiles. Dentro de los sésiles incluyó a las esponjas (Spongia) y los corales (Corallina). Los más interesantes, en nuestro caso, son los mótiles, comprendiendo éstos los géneros: Hydra, Pennatula, Taenia, Volvox, Furia y Chaos. El género Chaos (denominación más que sugerente de la dificultad de clasificar estos animalitos) se subdividía a su vez en las especies C. redivivum, C. protheus, C. fungorum, C. ustilago y C. infusorium. Por primera vez en la historia, los infusorios dejaban de ser un grupo sui generis de entes vivientes y se integraban, formalmente, a los animales dentro de un esquema clasificatorio universal. Debemos destacar que Linnaeus, al igual que el Estagirita, localizó decididamente a los zoofitos en el reino animal. Este hecho es destacable, pues Linnaeus era un firme partidario de la Gran Cadena de los Seres y, por tanto, ferviente partidario también de la gradualidad. Su famosa frase Natura non facit saltus (ya acuñada por John Ray en su obra Methodus Plantarum Nova de 1682) es un claro reflejo de ello. ¿Por qué Linnaeus no consideró, entonces, a los zoofitos como un reino intermedio? Ésta es una pregunta que hoy no sabemos responder. Tal vez, su incansable afán por establecer un orden claro y preciso en la naturaleza, superó su clara y explicita visión gradualista. Para la osada propuesta del famoso reino intermedio o Protista de Haeckel, se tendría que esperar aún casi una centuria ${ }^{6}$.

Los infusorios, desde su descubrimiento hasta los días de Linnaeus, eran considerados, fundamentalmente, "animalitos" ambientales exóticos, sin importancia práctica para el ser humano. Habitaban en toda clase de infusiones (té, pimienta, etc), aguas putrefactas, secreciones mucosas (saliva), semen, etc. Hasta dicho momento, nadie en el mundo académico había correlacionado la causa de las enfermedades infecciosas con la existencia de estos pequeñísimos animales. Debió aún pasar casi un siglo para que los trabajos del italiano Agostino Bassi (17731856), el francés Louis Pasteur (1822-1895) y el alemán Roberto Koch (1843-1910) establecieran sobre bases sólidas la teoría de los gérmenes infecciosos. Es en este contexto, entonces, cuando surge la genial y previsora visión de Linnaeus planteando una sexta especie, aún hipotética, llamada por él Chaos obscura. Es en esta categoría específica donde él plantea incluir los agentes infecciosos. La descripción que acompaña a esta especie en la duodécima edición de su obra Systema Naturae (1766) señala ${ }^{7}$ :

"Etiamnum latent plurimae moleculae vivae, quae forte ad hanc familiam spectant, posteris relinquendae" ("todavía se ocultan muchísimas moléculas vivas que tal vez deban ser dejadas a la posteridad poder develar").

Dentro de esta hipotética especie el menciona seis variedades o subespecies:

$\alpha$ Febrium Exanthematicarum contagium?

$\beta$ Febrium Exacerbantium caussa?

$\gamma$ Siphilitidis virus humidum?

$\delta$ Spermatici vermiculi Leuwenhoek?

$\varepsilon$ Aethereus nimbus mense florescentiae suspensus?

$\zeta$ Fermenti Putredinisque septicum Münchausen?

Claramente, para este insigne naturalista sueco, las causas de ciertas fiebres exan- 
temáticas y fiebres paroxísticas, la sífilis, los espermios e, increíblemente, también las etéreas nubes suspendidas en el cielo de primavera (aethereus nimbus mense florescentiae suspensus), se enmarcaban dentro de una misma categoría heterogénea y oscura que tan sólo la posteridad podría sistematizar. No debiera concluirse que Linnaeus pensara que este conjunto de seres tan disímiles estuviera de alguna manera relacionado; sino, más bien, que dada la falta de conocimiento que sobre ellos existía en ese momento, no eran del todo clasificables. Sin embargo, no pudiendo liberarse de su incansable espíritu sistematizador, le fue imposible dejarlos como entes aislados, sin clasificar y, por ello, se vio en la obligación de plantear una categoría artificial para todos ellos.

Linnaeus fue el primero en incorporar a los infusorios dentro de una visión global de los seres vivos. Hasta ese momento no eran más que una curiosidad académica y el énfasis de los pocos libros dedicados a ellos, era describir en detalle su proteiforme apariencia, sin importar su relación con otros seres vivos. Debemos, sin embargo, destacar que ya mucho antes que Linnaeus difundiera su sistema clasificatorio, algunos autores ya habían planteado, explícitamente, que algunas enfermedades podían ser causadas por diminutos agentes vivos. Desde la antigüedad existía la doctrina que atribuía ciertas enfermedades a pequeños animalitos invisibles. Por ejemplo, el afamado polígrafo romano Marco Terencio Varrón (116-26 a.C.) dice que se debe tener cuidado en construir una villa cerca de terrenos pantanosos, ya que cuando se secan dichos terrenos, pequeñísimos animales que el ojo no puede observar, penetran en el cuerpo por la boca y la nariz, propagando difíciles enfermedades ("animalia quaedam minuta quae non possunt oculi consequi et per aera intus in corpus per os ac nares perveniunt atque efficiunt difficilis morbos" $)^{8}$. Posteriormente en la Edad Moderna, siglos XVI y XVII, aparecen los célebres Girolamo Fracastoro (1478-1553) y Athanasius Kircher (16021680). Fracastoro habló en su obra De contagione (1546) sobre semillas (seminaria) de enfermedad para explicar el contagio de las enfermedades epidémicas ${ }^{9}$. Kircher también tenía la creencia en lo denominado, en ese entonces, pathologia animata, esto es, que las enfermedades infecciosas eran producidas por diminutos agentes vivientes que ingresaban al organismo humano. En su obra Scrutinium physico-medicum pestis (1658) describió, con la ayuda de un microscopio compuesto, pequeñísimos gusanos en la sangre de víctimas de la peste. Sin embargo, hoy se cree que, probablemente, sus observaciones correspondían más bien a hematíes y no a la bacteria Yersinia pestis, agente causal de dicha enfermedad. Por otra parte, la publicación $A$ new theory of consumptions: more especially of a phthisis or consumption of the lungs (London, 1722) del inglés Benjamín Marten ${ }^{10}$, en la cual postulaba como causa de la tuberculosis a ciertos animalcules, fue totalmente ignorada en su época. Marten postuló, específicamente en dicha obra, que la causa original de la tuberculosis: "may possibly be some certain species of animalcula or wonderfully minute living creatures that by their peculiar shape or disagreeable parts are inimicable to our nature.....". En otro lugar considera la posible existencia de miríadas de animales diferentes a los conocidos naturalmente: "infinitely smaller and wholly imperceptible to our eye though assisted by the best glasses that can be made".

Frente a estos visionarios precursores, el gran mérito de Linnaeus fue, desconociendo al parecer los trabajos previos mencionados, incorporar estos extravagantes seres descubiertos por Leeuwenhoek dentro de una clasificación universal de los seres vivos, sugerir su relación con ciertas enfermedades infecciosas e interesar al mundo académico en tales conceptos, los cuales gracias a su enorme prestigio, fueron ampliamente divulgados y discutidos.

Finalmente, en la actualidad, aceptamos una clasificación universal tripartita de los seres vivos propuesta por Woese y colaboradores en $1990^{11}$. Se reconocen tres dominios de seres vivos: dominio Bacteria, Arquea y Eucaria. Se dice que los arquea no son ni bacterias ni eucariontes, sino más bien una forma intermedia entre bacterias y eucariontes. Son procariontes, pero de una naturaleza intermedia, pues su sistema informacional (síntesis de ADN, transcripción y traducción) es paradojalmente de tipo eucarionte. Por tanto, la dicotomía básica entre procariontes y eucariontes no sería válida.

¡Nuevamente, estos modernos zoofitos rompen la milenaria tendencia dicotómica que ha dominado el mundo biológico desde la antigüedad y exigen su propio reino intermedio en la cadena de los seres, siguiendo el espíritu instaurado por Haeckel en 1866!

\section{Resumen}

Los zoofitos son por definición organismos con características intermedias entre plantas y animales. El concepto ya se encuentra esbozado por Aristóteles en su obra Historia Animalium. En el siglo XVIII, el gran naturalista sueco Carolus Linnaeus en la décima edición de su Systema Naturae localizó al orden Zoophyta dentro de la clase Vermes. En dicha clasificación, por primera vez, los extravagantes animálculos (infusorios) descubiertos por van Leeuwenhoek a fines del siglo XVII, fueron clasificados formalmente como zoofitos, siendo incorporados, en forma específica, dentro del género Chaos. Audazmente, Linnaeus conjeturó, además, que los agentes infecciosos podrían estar relacionados con los animálculosinfusorios, dejando, sin embargo, para la posteridad, tal demostración.

\section{Agradecimientos}

A mi padre Javier Osorio Naranjo por su inestimable ayuda en la traducción de los textos latinos.

\section{Referencias}

1.- Aristóteles. Investigación sobre los animales. Libro VIII, 588b. Editorial Gredos S.A., Madrid, España, 1992.

2.- Dillon J. Dexippus on Aristotle's categories. Pág 90. Nota 51. Cornell University Press 1990.

3.- Ragan M. A third kingdom of eukaryotic life: history of an idea. Arch Protistenkd 1997; 148: 225-43.

4.- Rondeletius [Rondelet] G. Libri de Piscibus Marinis, in quibus verae Piscium effigies expressae sunt. Quae in tota Piscium Historia Contineantur, indicat Elenchus 
Pagina Nona \& Decima. Lugduni [Lyon], 1554. Documento Digital: Gottinger Digitalisierungs-Zentrum: http://gdz.sub.unigoettingen.de/de/index.html. (Accedido: octubre de 2006).

5.- Dobell C. Antony van Leeuwenhoek and his little animals. Being some account of the father of Protozoology and Bacteriology and his multifarious discoveries in these disciplines. Constable and Company Ltd., London 1932. Dover Publications Inc., New York, 1960.

6.- Haeckel E. Generelle Morphologie der
Organismen. Verlag Georg Reimer, Berlin, 1866.

7.- Linnaeus C. Systema Naturae per Regna Tria Naturae, Secundum Classes, Ordines, Genera, Species, cum Characteribus, Differentiis, Synonymis, Locis. Tomus I, Editio Duodecima, Reformata, 1766. Documento digital: Gallica, Biblioteca Nacional de Francia: http://gallica.bnf.fr/. Fecha de acceso a información: octubre de 2006.

8.- Varrón M T. Rerum rusticarum de Agri Cultura, 116-27 A.C. Documento digital: http://www.readme.it/libri/2/2048022.shtml.
(Accedido: octubre de 2006)

9.- Bulloch W. The History of Bacteriology. Oxford University Press, First Edition, London, England, 1938.

10.- Doetsch R. Benjamin Marten and His "New Theory of Consumptions. Microbiol Rev 1978; 42: 521-8.

11.- Woese C R, Kandler O, and Wheelis M L. Towards a natural system of organisms: Proposal for the domains Archaea, Bacteria, and Eucarya. Proc Natl Acad Sci USA 1990; 87: 4576-9. 